PontIFícIA UNIVERSIDADE CATÓLICA DO RIO DE JANEIRO

\title{
A Educação Corporativa e os princípios de sucesso de Eboli Caso Azul Linhas Aéreas Bruno Gonçalves Molinari
}

Trabalho de Conclusão de Curso

CENTRO de CIÊNCIAS SOCIAIS - CCS

DePARTAMENTO de AdMINISTRAÇÃo

Graduação em Administração de Empresas 
Bruno Gonçalves Molinari

A Educação Corporativa e os princípios de sucesso de Eboli

\author{
Caso Azul Linhas Aéreas
}

Trabalho de Conclusão de Curso

Trabalho de Conclusão de Curso, apresentado ao programa de graduação em Administração da PUC-Rio como requisito parcial para a obtenção do titulo de graduação em Administração.

Orientador (a): Patrícia Ítala Ferreira

Rio de Janeiro

Novembro de 2018 
Adquirir a sabedoria é uma coisa mais importante que você pode fazer; em tudo mais, aprenda a ter discernimento. Se você der valor à sabedoria, ela o engrandecerá; abrace-a, e ela o honrará. 


\section{AGRADECIMENTOS}

Em primeiro lugar à Deus, por me capacitar e me fortalecer a cada dia. Não foi fácil chegar até aqui, mas sem Ele não seria possível estar onde estou. Também agradeço à Deus pela vida da minha esposa, pois sem ela eu não teria ingressado na faculdade. Agradeço a ela também por me amar e acreditar em mim. Agradeço por me incentivar a não fazer as coisas do meu jeito, e sim do jeito certo.

Aos meus colegas de trabalho que contribuíram com a pesquisa.

À Azul Linhas Aéreas por me proporcionar ter essa experiência de frequentar uma universidade corporativa com funcionários tão capacitados. Um agradecimento à UniAzul também por abrir as portas para esse estudo.

Aos meus amigos Sergio e Cynthia Porral, Saulo e Stefane Fajardo, Ivy Vieira, Diego e Fernanda Moura, pelos conselhos e por me apoiarem.

Aos amigos que a PUC me deu, Toni Luigi Scorza, Rafael Asvolinsque, Henrique Rangel, Pablo Andreas, Cristiana Souza e tantos outros que foram muito importantes em minha caminhada acadêmica.

Aos meus professores pela excelência no ensino e experiências compartilhadas que me motivaram a não desistir.

Em especial, à minha orientadora... você não existe! Muito organizada, e minunciosamente excelente. Fiz a escolha certa! Um agradecimento também à Cacau e Luna por me emprestarem sua mãe! 


\section{Resumo}

Gonçalves Molinari, Bruno. A Educação Corporativa e os princípios de sucesso de Eboli: Caso Azul Linhas Aéreas. Rio de Janeiro, 2018. 46 p. Trabalho de Conclusão de Curso - Departamento de Administração. Pontifícia Universidade Católica do Rio de Janeiro.

A universidade corporativa surge em meio a um cenário onde 0 conhecimento se torna obsoleto cada vez mais rápido, exigindo das empresas uma maior agilidade nas tomadas de decisão. Esse mesmo conhecimento, se bem trabalhado, se transforma em vantagem competitiva no mundo corporativo.

Este estudo visa identificar e analisar, sob a ótica dos agentes de atendimento em aeroportos da Azul Linhas Aéreas, as ações da UniAzul, a universidade corporativa da empresa, considerando os sete princípios norteadores para o sucesso de um sistema de educação corporativa de Eboli (2004). Para tal foi realizada uma pesquisa de campo através de um questionário e de entrevistas, buscando informações sobre a percepção desses funcionários sobre o serviço prestado pela UniAzul. Entre os resultados mais expressivos pode-se citar o princípio de perpetuidade.

Palavras-chave: Educação Corporativa, Universidade Corporativa, Sete princípios de sucesso.

\section{Abstract}

Gonçalves Molinari, Bruno. Corporate Education and the príncipes of success proposed by Eboli: Case of Azul Linhas Aéreas. Rio de Janeiro, 2018. 46 p. Trabalho de Conclusão de Curso - Departamento de Administração. Pontifícia Universidade Católica do Rio de Janeiro.

The corporate university arises in the middle of a scenario where knowledge becomes obsolete faster and faster, requiring companies to be more agility in decision making. That same knowledge, if well done, becomes a competitive advantage in the corporate world. This study aims to identify and analyze the actions of UniAzul, the corporate university of the company, considering the seven guiding principles for the success of a corporate education system, proposed by Eboli (2004), from the point of view of airport service agents 
at Azul Linhas Aéreas. For that, a research zone was conducted through a questionnaire and interviews, seeking information about the perception of these employees about the service provided by UniAzul. Among the most expressive results we can mention the principle of perpetuity.

Key-words: Corporate Education, Corporate University, Seven guiding principles for the success 


\section{Sumário}

1. O tema e o problema de estudo 10

1.1. Introdução ao tema e ao problema do estudo 10

1.2. Objetivo do estudo 11

1.3. Objetivos intermediários do estudo 11

1.4. Delimitação e foco do estudo 12

1.5. Justificativa e relevância do estudo 12

2 . Revisão de literatura 13

2.1. Educação Corporativa 13

2.2. Os sete princípios de sucesso de um sistema de Educação

$\begin{array}{ll}\text { Corporativa } & 17\end{array}$

2.2.1. Competitividade 18

$\begin{array}{lr}\text { 2.2.2. Perpetuidade } & 19\end{array}$

$\begin{array}{ll}\text { 2.2.3. Conectividade } & 19\end{array}$

2.2.4. Disponibilidade 20

2.2.5. Cidadania 20

$\begin{array}{ll}\text { 2.2.6. Parceria } & 21\end{array}$

2.2.7. Sustentabilidade 22

2.2.7.1. O desafio da avaliação de treinamentos 23

3 . Métodos e procedimentos de coleta e de análise de dados do estudo26

3.1. Etapas de coleta de dados e fontes de informação 26

3.2. Procedimentos e instrumentos de coleta de dados 27

3.3. Formas de tratamento e análise dos dados coletados para o estudo28

3.4. Limitações do Estudo

4. Apresentação e análise dos resultados 29

4.1. A Empresa 29

4.2. Descrição e Análise dos resultados 30

4.2.1. Análise dos resultados 32 
5 Conclusões e recomendações para novos estudos

Apêndice 2

Apêndice 3

Apêndice 4

\section{Lista de figuras}

Figura 1 - Cinco forças de Meister

Figura 2 - Os sete princípios de Eboli

Figura 3 - O papel das instituições de ensino superior e das universidades corporativas

Figura 4 - Tempo de empresa dos respondentes do questionário 31

Figura 5 - Quantidade de visitas à UniAzul 31

Figura 6 - Indicadores de Desempenho UniAzul 40

Figura 7 - Presença dos princípios de Eboli (2004) na UniAzul 42 


\section{Lista de Tabelas}

Tabela 1- Dados dos entrevistados............................................. 31

Tabela 2 - Resultado das perguntas sobre Competitividade................... 32

Tabela 3 - Resultado das perguntas sobre Perpetuidade ...................... 33

Tabela 4 - Resultado das perguntas sobre Conectividade...................... 34

Tabela 5 - Resultado das perguntas sobre Disponibilidade .................... 35

Tabela 6 - Resultado da pergunta sobre Cidadania .............................37

Tabela 7 - Resultado das perguntas sobre Parceria ............................ 38

Tabela 8 - Resultado das perguntas sobre Sustentabilidade .................. 39 


\title{
1. O tema e o problema de estudo
}

Este capítulo apresenta o tema deste estudo, o problema de pesquisa, o objetivo deste trabalho, a delimitação e sua relevância.

\subsection{Introdução ao tema e ao problema do estudo}

\begin{abstract}
A educação é instrumento necessário às mudanças crescentes e ao desenvolvimento no país. Se por um lado é inquestionável sua importância, por outro, a falta de investimento na qualificação e educação da força de trabalho é um dos maiores obstáculos encontrados para o progresso. (EBOLI, 2008, p.2)
\end{abstract}

Classificada com um avanço do estilo tradicional de treinamento (BAYMA, 2005), a educação corporativa surge num cenário de frequentes mudanças e necessidade de respostas rápidas para “(...) lidar com panoramas inovadores, modificando continuamente as práticas gerenciais adotadas e identificando novos perfis de competências para atender a novas demandas. " (PEREIRA et al, 2006, p.1)

Desde a Revolução Industrial, a formação de pessoas teve como objetivo inicial apenas preparar os funcionários para realizar suas tarefas. Com o passar dos anos, foram surgindo os programas educacionais nas empresas, mas estes eram direcionados apenas aos níveis gerenciais. Hoje em dia, tem-se a capacitação profissional através da informação e do conhecimento como estratégia competitiva. (EBOLI, 2008)

Educação Corporativa é um sistema de formação de pessoas pautado pela gestão de pessoas com base em competências, devendo, portanto, instalar e desenvolver nos colaboradores internos e externos as competências consideradas críticas para a viabilização das estratégias de negócio, promovendo um processo de aprendizagem ativo e permanente, vinculado aos propósitos, valores, objetivos e metas empresariais. (EBOLI, 2008, p.9)

Eboli (2004) afirma que, para se constituir um sistema de educação corporativa bem-sucedido, é necessário seguir princípios, ou seja, bases que direcionam e dão origem a um plano estratégico de qualidade. Para que a estratégia se concretize, são necessárias escolhas organizacionais integradas, 
sob um entendimento cultural, estrutural, tecnológico e processual, baseados em um modelo de gestão empresarial. Essas escolhas devem transformar os princípios escolhidos em ações, hábitos e exercícios corporativos, gerando um comportamento de acordo com a estratégia definida. "Ou seja, as práticas são as escolhas organizacionais que propiciam transformar as escolhas estratégicas (competências empresariais) em escolhas pessoais (competências humanas). (EBOLI, 2004, p. 6)

A autora definiu também sete princípios de sucesso para um sistema de educação corporativa, originando uma metodologia para se conceber, implantar e analisar projetos de universidades corporativas.

$O$ presente estudo tem como objeto de pesquisa a universidade corporativa da Azul Linhas Aéreas, a UniAzul, situada em Campinas, no estado de São Paulo. Criada praticamente após a fundação da empresa, em 2008, a UniAzul é considerada hoje o mais amplo centro de treinamento de profissionais do setor em toda a América Latina.

Pode-se destacar como objetivos da UniAzul: manter todos os profissionais preparados para exercerem suas atividades com a mais alta capacidade técnica, buscando a excelência na prestação de serviço ao cliente; perpetuar a cultura da Azul e integrar as pessoas que passam pelos cursos presenciais.

A partir do que já foi exposto, este estudo pretende responder a seguinte pergunta: Como é a atuação da UniAzul, sob a ótica dos funcionários do setor de Aeroportos da Azul, considerando os sete princípios de Eboli (2004)?

\subsection{Objetivo do estudo}

O objetivo do estudo é identificar e analisar qual é a percepção dos empregados do setor de Aeroportos da Azul, sobre a atuação da UniAzul considerando os sete princípios norteadores para o sucesso de um sistema de educação corporativa propostos por Eboli (2004).

\subsection{Objetivos intermediários do estudo}

Com a finalidade de atingir o objetivo proposto, esse estudo prevê os seguintes objetivos intermediários:

- Apresentar o conceito de universidade corporativa;

- Apresentar os princípios de Educação Corporativa propostos por Eboli (2004); 
- Estudar a UniAzul e suas práticas;

- Realizar uma pesquisa de campo para identificar os princípios propostos por Eboli (2004) na Uniazul.

\subsection{Delimitação e foco do estudo}

Este estudo visa identificar e analisar as ações da UniAzul de acordo com os princípios de Eboli (2004) sob o enfoque dos funcionários da Azul da área de Aeroportos do Aeroporto Santos Dumont, com o cargo de agente de atendimento. $\mathrm{O}$ profissional com esse cargo é responsável por toda a parte de atendimento ao cliente, bem como o monitoramento de pousos e decolagens, a fim de ter todas as informações necessárias para fornecer aos clientes e manter o bom funcionamento da operação.

O estudo foi realizado entre agosto e novembro de 2018, no Aeroporto Santos Dumont, que fica localizado no Rio de Janeiro.

Exclui-se desse estudo outras áreas da empresa, a opinião de outras empresas aéreas e suas universidades corporativas.

A percepção dos funcionários será avaliada por meio de um questionário e de entrevistas, baseados nos princípios de Eboli (2004).

\subsection{Justificativa e relevância do estudo}

Os programas educacionais de uma educação corporativa devem estar alinhados à estratégia da empresa. A avaliação desses programas torna possível averiguar o alinhamento dos cursos aos objetivos organizacionais. (SANTOS, 2016)

O presente estudo será útil para a empresa e seus gestores, pois busca analisar e propor melhorias à metodologia atual empregada na UniAzul, podendo ser utilizado para uma possível revisão do modelo empregado.

Torna-se também relevante para os funcionários da empresa, pois é uma forma de expressar sua opinião sobre o serviço prestado pela UniAzul, o que pode vir a se tornar um instrumento de mudança na organização.

Por fim, também há a importância para o campo acadêmico, visto que o acervo de produção textual referente a esse assunto será enriquecido, podendo ser utilizado como iniciativa e base para novos estudos. 


\section{Revisão de literatura}

"Educar é muito mais que encher uma vasilha vazia. É acender uma luz na mente das pessoas. Eu diria que educar é ensinar a pensar. Nós sabemos muito hoje. " (BOFF, 2005, p.7)

Hoje em dia, o ser humano adquire muito conhecimento, porém pensa muito pouco sobre o que se aprende. No atual cenário, faz-se necessário aprender a pensar paralelamente à absorção de dados, para que se possa inovar e ter argumentos para criticar o que se é proposto, a fim de não se tornar uma esponja de conhecimento sem um concreto uso. (BOFF, 2005)

Eboli (2004) afirma que a educação é algo que interessa à toda sociedade, inclusive o meio corporativo. Se uma empresa deseja aumentar sua competitividade, deve estar empenhada no desenvolvimento da educação.

Com isso, afirma-se que "As universidades corporativas que vão se multiplicando em todo o mundo são apenas respostas naturais do processo evolutivo humano. " (MORHY, 2005, p. 13)

\footnotetext{
Estamos transitando da era do trabalho braçal para a do trabalho mental, intelectual. Alguns dizem que estamos passando da era da mão-de-obra para a da mente-de-obra. Prefiro dizer que estamos transitando da era da mão-de-obra para a era da mente criadora e libertadora. Devemos então ler, aprender, analisar, criticar e planejar sempre, e mais. (MORHY, 2005, p. 12)
}

Nesse novo ambiente, Eboli (2004) afirma que deverá ser adotada uma postura voltada para o autodesenvolvimento e à aprendizagem contínua e, para isso, as empresas necessitarão de sistemas educacionais que tenham como foco o desenvolvimento de atitudes, posturas e habilidades, e não apenas conhecimento técnico.

As linhas abaixo tratarão sobre a Educação Corporativa, sua origem, características e princípios.

\subsection{Educação Corporativa}

Segundo Bayma (2005), a educação corporativa é uma evolução incremental do programa de treinamento e desenvolvimento, ao passo que há 
uma criação e uma adaptação dos princípios que estão presentes na rotina de treinamento empresarial.

A criação do conceito de Universidade Corporativa (UC) está relacionado com o aumento da complexidade das exigências atuais do mercado, tornando-o mais competitivo. Faz-se necessário, então, funcionários mais habilidosos e capazes, forçando a empresa a criar programas para formar profissionais com as expertises necessárias para esse novo cenário. (BAYMA, 2005)

Eboli (2004) afirma que as UC's surgiram no final do século XX, fundindo duas perspectivas: a Escola Clássica, onde o foco era dirigido às classes dominantes, enfatizando a ideologia do modo de ser e pensar, e a Escola Profissionalizante, que é voltada para as classes instrumentais e dominadas, focando no modo de fazer. A UC procura desenvolver nos profissionais dos mais diversos públicos e categorias tanto os elementos ideológicos como os tecnológicos.

\footnotetext{
"Nessa nova visão empresarial sobre o componente humano, o objetivo dos programas de educação corporativa deve ser o de aumentar o capital intelectual (Cl), ativo que não aparece nos balanços financeiros das empresas. " (BAYMA, 2005, p.25 apud SOUZA, 2000)
}

A mudança de foco na gestão empresarial, ou seja, a passagem do modo taylorista/fordista de se administrar para um cenário de gestão flexível, segundo Eboli (2004), gerou um forte impacto no comportamento das organizações. Houve uma alteração na estrutura das empresas, de verticalizadas e centralizadas para horizontalizadas e descentralizadas, e também no modo em que as tarefas são executadas, deixando de ser fragmentadas e padronizadas para se tornarem integrais e complexas, exigindo maior capacidade de pensar, decidir e agir simultaneamente.

"A hierarquia corporativa, antigamente estável e de movimentos lentos, com os 'pensadores' no topo da pirâmide, e os 'fazedores' na base, é pouco apropriada ao novo ambiente competitivo e de movimentos rápidos. " (MEISTER, 1999, p.2)

Pode-se afirmar que a área de treinamento e desenvolvimento teve uma grande importância nos últimos anos no Brasil e, ao se iniciar o processo de migração para uma estrutura de UC, obteve-se foco e força estratégica, se firmando como um dos pilares de uma gestão corporativa bem-sucedida. (EBOLI, 2005)

Meister (1999) afirma que existem cinco forças que sustentam a importância da implementação das UC's, como descrito na figura 1. 
Figura 1 - Cinco forças de Meister
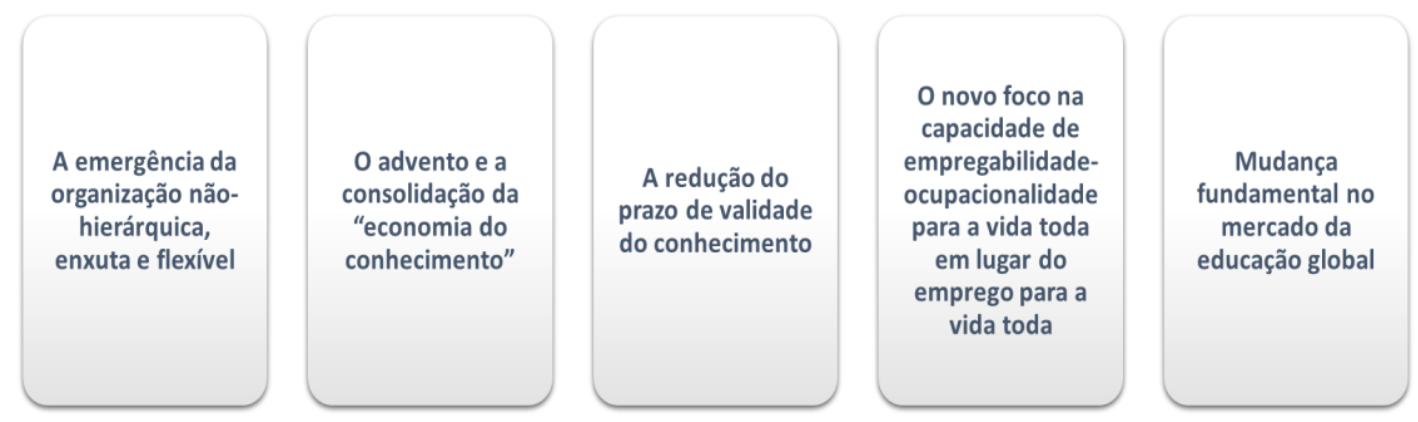

Fonte: Adaptado de Meister (1999)

A educação corporativa é descrita por Bayma (2005) como um avanço em relação aos programas de treinamento tradicionais, uma vez que proporciona 0 desenvolvimento de competências de acordo com as estratégias da empresa, que representam o foco e o fator estimulante para o aprendizado.

Apesar de ser descrita como uma evolução, o conceito de UC torna-se diferente do conceito de treinamento e desenvolvimento (T\&D) visto que está voltada para um programa de educação e desenvolvimento interno e externo. As estratégias da empresa devem ser respeitadas, a fim de manter sua vantagem competitiva, buscando um aprendizado permanente e alavancando essa vantagem. Torna-se fundamental o desenvolvimento das competências profissionais, técnicas e gerenciais que são essenciais para viabilizar as estratégias de negócios. (BAYMA, 2005)

Eboli (2004) afirma que se faz necessário o diagnóstico de competências essenciais, divididas em três níveis:

- Empresarial: Competências já existentes ou a adquirir, para que a empresa consolide e aumente sua capacidade de atuar de forma diferenciada e com excelência.

- Organizacional: Competências que, ainda no âmbito empresarial, precisam ser desenvolvidas nos principais segmentos de negócios para sustentar as competências empresariais.

- Humana: Competências a se desenvolver individualmente para que haja êxito nos objetivos estratégicos.

Deve-se salientar que programas educacionais nas empresas sempre existiram, mas normalmente eles eram restritos aos níveis gerenciai se à alta administração. Para a grande maioria dos funcionários havia programas de treinamento pontuais. Na medida em que o surgimento das 
UC's foi o grande marco da passagem do tradicional Centro de Treinamento \& Desenvolvimento (T\&D) para uma preocupação mais ampla e abrangente com a educação de todos os colaboradores de uma empresa, na prática é com o seu advento que vem à tona a nova modalidade de Educação Corporativa. (EBOLI, 2004, p.2)

A mudança no foco do antigo sistema de treinamento para a UC gerou um grande impacto no gerenciamento da carreira do profissional. Antes, existia um cenário onde a carreira do empregado era controlada por sua empresa, seguindo uma linha paternalista, alinhando as expectativas dos empregados com as da empresa. Hoje em dia, Lopes (2005) afirma que o empregado controla sua própria carreira, buscando sempre estar atualizado e gerando valor para sua empregabilidade, fugindo assim do risco de ficar obsoleto no mercado.

Ainda segundo o autor, fica a cargo da empresa prover o acesso de seus empregados ao conhecimento, tornando-se um diferencial de uma empresa flexível e globalizada. Tal conhecimento deixa de ser estritamente presencial para se tornar virtual, aumentando sua acessibilidade. Os ativos físicos (empregados) são algo que toda empresa possui, a diferença que gera uma vantagem competitiva é como a empresa gera o conhecimento e o transmite ao seu empregado.

\footnotetext{
Muitas empresas testemunharam uma redução radical no prazo de validade do conhecimento e começaram a perceber que não mais podiam depender das instituições de ensino superior para desenvolver sua força de trabalho. Decidiram então, partir para a criação de suas próprias "Universidades Corporativas" com o objetivo de obter um controle mais rígido sobre o processo de aprendizagem, vinculando de maneira mais estreita os programas de aprendizagem a metas e resultados estratégicos reais da empresa. (MEISTER, 1999, p.1)
}

"A meta da educação corporativa é aumentar a produtividade da força de trabalho e criar uma vantagem competitiva em nível de mercado(...). Aprender mais rapidamente que os concorrentes é o grande desafio da empresa deste século." (LOPES, 2005, p.141)

Em outro ponto sobre a UC, Lopes (2005) afirma que atualmente a educação é permanente, personalizada e just-in-time, ou seja, a disponibilidade do conhecimento está de acordo com a sua necessidade. Não é preciso que o funcionário receba uma carga excessiva e massiva de conhecimento, pois, no dia seguinte, ele pode ter a necessidade de reciclar esse conhecimento. 
Com isso, a UC traz um método de Educação à Distância (EAD), onde através de um suporte eletrônico, o conteúdo a ser aprendido está à disposição do profissional no momento que ele necessitar. Isso torna a aprendizagem permanente, e transforma o treinamento em algo gerenciável pela empresa. (LOPES, 2005)

A educação corporativa não é um modismo, é importante esgotar esse fato. Ela veio para ficar desde que em 1955 foi utilizada pela primeira vez pela General Eletric. Alguns fatores, entretanto, contribuíram para que a sua presença se tornasse mais marcante no fim do século XX e no início do século XXI: a redução drástica da validade do conhecimento e a globalização da economia do conhecimento, que exige uma força de trabalho altamente qualificada. (LOPES, 2005, p.143)

Ainda segundo o autor, as UCs possuem recursos tecnológicos avançados, como internet, videoconferência, etc, e, como resultado disso, há uma maior acessibilidade e interatividade em relação ao conhecimento ministrado, através de um campus virtual.

A seguir serão detalhadas as características de uma UC que Eboli (2004) descreve como princípios de sucesso de um sistema de Educação Corporativa.

\subsection{Os sete princípios de sucesso de um sistema de Educação Corporativa}

Figura 2 - Os sete princípios de Eboli

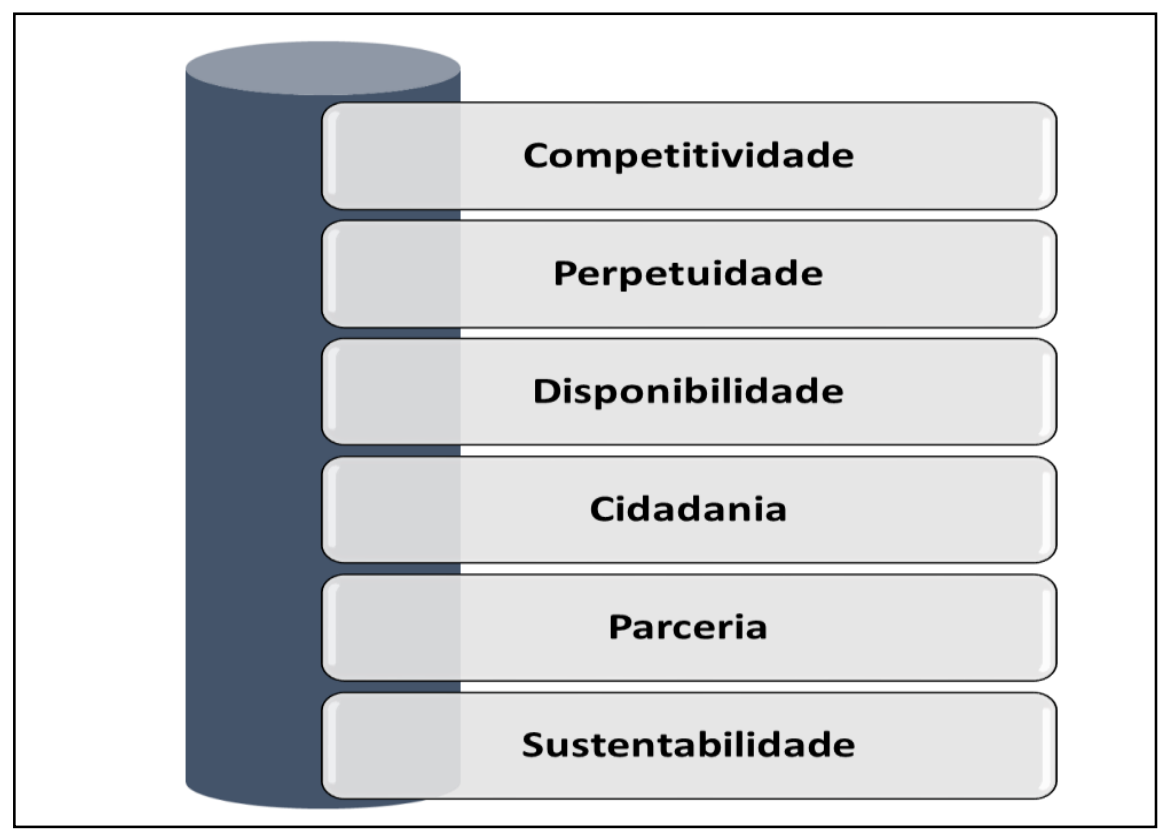

Fonte: Adaptado de Eboli (2004) 
Segundo Eboli (2005), existem sete princípios que devem ser seguidos durante a elaboração de um sistema de UC, tal como ilustrado na figura 2.

"A qualidade de um Sistema de Educação Corporativa depende da qualidade de pensamento de seus idealizadores, que deve ser balizado pelos sete princípios aqui apresentados." (EBOLI, 2005, p.94)

\subsubsection{Competitividade}

Valorizar a educação como forma de desenvolver o capital intelectual dos colaboradores, transformando-os efetivamente em fator de diferenciação da empresa diante dos concorrentes, ampliando assim sua capacidade de competir. Significa buscar continuamente elevar 0 patamar de competitividade empresarial por meio da instalação, desenvolvimento e consolidação das competências críticas empresariais e humanas. (EBOLI, 2004, p.85)

Segundo a autora, todos os empresários buscam adquirir vantagens competitivas para que suas empresas estejam à frente dos concorrentes. Além disso, é ideal que essas vantagens sejam difíceis de se reproduzir.

\footnotetext{
Nesse contexto, aprendizagem, formação e gestão de competências são conceitos centrais que, operacionalizados na prática das organizações, se transformam em vantagens competitivas. A empresa passa a ser vista, assim, não apenas como um portfólio de produtos e serviços, mas também um portfólio de competências. (EBOLI, 2004, p.89)
}

Eboli (2004, apud PRAHALAD, 1995) afirma que o foco de uma estratégia empresarial é o desenvolvimento de uma série de competências essenciais para, posteriormente, prospectar a criação de novos produtos e serviços.

Ainda segundo a autora, o objetivo principal do sistema de UC é desenvolver competências críticas para viabilizar estratégias empresariais, ou seja, para que se possa elaborar um projeto bem-sucedido é de suma importância que as ações educacionais sejam desenhadas com base nas competências críticas. 


\title{
2.2.2.Perpetuidade
}

\begin{abstract}
Entender a educação não apenas como um processo de desenvolvimento e realização do potencial existente em cada colaborador, mas também como um processo de transmissão da herança cultural, a fim de perpetuar a existência da empresa. (EBOLI, 2004, p.115)
\end{abstract}

De acordo com a autora, a UC é um dos principais instrumentos de consolidação da cultura empresarial e, com isso, os responsáveis pelos programas educacionais devem definir estratégias que transmitam a cultura da organização.

Ainda segundo a autora, pensar sobre qual a força que uma UC tem para integrar e transformar traços, valores e princípios de uma empresa é fundamental para a construção de uma cultura organizacional pautada em aprendizagem e autodesenvolvimento contínuo.

\subsubsection{Conectividade}

Privilegiar a construção social do conhecimento, estabelecendo conexões e intensificando a comunicação e a interação. Objetiva ampliar a quantidade e a qualidade da rede de relacionamentos com o público interno e externo. (EBOLI, 2004, p.125)

A autora afirma que o desafio para as empresas realmente competitivas não é mais apenas produzir bens e serviços, mas implantar e desenvolver atividades que gerem soluções que possam se integrar, mas não de forma restrita a clientes e consumidores, e sim aberta a toda cadeia de valor.

Eboli (2014) afirma ainda que o modelo de gestão do conhecimento não pode ser focado apenas no aspecto tecnológico. O modelo deve englobar a liderança e as equipes para que o sistema ganhe vida e conquiste seus objetivos, pois a empresa como um todo deve ter influência na geração e transferência desse conhecimento no processo de aprendizagem organizacional. 


\title{
2.2.4.Disponibilidade
}

\begin{abstract}
Oferecer e disponibilizar atividades e recursos educacionais de fácil uso e acesso, propiciando condições favoráveis para que os colaboradores realizem a aprendizagem a qualquer hora e em qualquer lugar. (EBOLI, 2004, p.145)
\end{abstract}

Eboli (2004) afirma que as UC's surgiram em um cenário onde o conhecimento é a base para a formação de riquezas individuais, empresariais e nacionais e onde se encontra um conteúdo educacional que se torna obsoleto cada vez mais rápido.

Conforme já mencionado na seção anterior, Eboli afirma que muitas UC's utilizam a tecnologia para realizar o aprendizado no estilo “(...) a qualquer hora e em qualquer lugar" (EBOLI, 2004, p.145). As UC's que tiveram melhores resultados até então foram as que se fundamentaram na EAD e no uso intenso de tecnologia em diversos formatos, a fim de gerar um ambiente organizacional favorável a uma aprendizagem ativa, contínua e compartilhada.

A autora afirma que algumas empresas têm encontrado dificuldades em oferecer com qualidade o trinômio conteúdo-tecnologia-serviços que atendam às necessidades da empresa. "Por outro lado, muitas vezes as próprias organizações não conhecem com clareza suas necessidades nessa área" (EBOLI, 2004, p.148)

\subsubsection{Cidadania}

\begin{abstract}
Estimular o exercício da cidadania individual e corporativa, formando atores sociais, ou seja, sujeitos capazes de refletir criticamente sobre a realidade organizacional, de construí-la e modifica-la e de atuar pautados por postura ética e socialmente responsável. (EBOLI, 2004, p. 171)
\end{abstract}

Eboli (2004) afirma que, no mundo corporativo, a preocupação com o tema cidadania empresarial está ganhando espaço na agenda das empresas, pois elas são estimuladas a ter uma postura firme e inovadora diante de assuntos éticos e de responsabilidade social, a fim de melhorar a qualidade da relação empresa-sociedade.

A autora afirma ainda que o exercício da cidadania individual e corporativa tem se mostrado uma prática eficaz no desenvolvimento de pessoas competentes.

Uma das metas da UC é que a cidadania corporativa esteja presente no seu currículo, pois esse tipo de ação traz benefícios como: estímulo do orgulho 
do funcionário e o fortalecimento do seu vínculo com a empresa; contribuição na construção de uma relação mais saudável entre líder e equipe e entre empresa e outras organizações; atração e manutenção de funcionários com bom potencial. (EBOLI, 2004, apud MEISTER, 1999)

\title{
2.2.6.Parceria
}

\author{
"Entender que desenvolver continuamente as \\ competências dos colaboradores é uma tarefa complexa, \\ exigindo que se estabeleçam parcerias internas (com líderes e \\ gestores) e externas (instituições de nível superior). " (EBOLI, \\ 2004, p. 181)
}

O princípio de parceria é dividido pela autora em parceria interna, onde há o estabelecimento de uma relação de parceria com líderes e gestores, a fim de que se responsabilizem pelo desenvolvimento dos funcionários; e parceria externa, onde há acordos com universidades e instituições de ensino superior, ou até clientes e fornecedores que possam trazer valor à UC, focando na qualificação da força de trabalho.

Ao analisar as melhores práticas de UC, a autora evidencia a importância de a liderança da empresa assumir seu papel na educação dos funcionários, por serem agentes que disseminam a cultura organizacional e também por se tornarem exemplos por sua postura, que, num cenário ideal, deve ser exemplar. O comportamento do líder deve ser buscado e seguido por seus liderados.

A autora diz que os gestores devem estar prontos para desempenhar seu papel como educadores na rotina diária de trabalho, para que seja gerado um ambiente onde a equipe se sinta motivada em utilizar todo o seu potencial na empresa.

Eboli (2004) afirma que as UC's devem desenvolver programas que façam com que os líderes e gestores revejam seu comportamento perante sua equipe durante o trabalho, focando na dualidade do mundo real e o mundo ideal.

"Trabalhar, aprender e educar estarão cada vez mais associados e integrados à vida corporativa, e a prática exemplar da liderança educadora será o alicerce para a construção do ideal organizacional almejado" (EBOLI, 2004, p.183)

Ao tratar sobre parcerias externas, a autora expõe que há uma polémica em chamar a UC de universidade, visto que ela não é reconhecida pelo Ministério da Educação como uma instituição de ensino superior, e sim um curso de aprimoramento voltado para as necessidades da empresa. 
Manter atualizado o conhecimento de um funcionário é uma tarefa que, segundo a autora, exige que a UC se una a instituições de ensino e concilie os objetivos do funcionário, da empresa e da instituição, abrangendo o desenvolvimento de programas de ensino e graduação personalizados e a criação de um consórcio de parceria de aprendizado.

A figura 3 mostra o papel das instituições de ensino superior e das universidades corporativas.

Figura 3 - $O$ papel das instituições de ensino superior e das universidades corporativas

\begin{tabular}{l|l}
\hline \multicolumn{1}{c|}{ Instituições de Ensino Superior } & \multicolumn{1}{c}{ Universidades Corporativas } \\
\hline $\begin{array}{l}\text { Desenvolve competências para o mundo do } \\
\text { trabalho }\end{array}$ & $\begin{array}{l}\text { Desenvolve competências para o mundo do } \\
\text { negócio }\end{array}$ \\
\hline $\begin{array}{l}\text { Propicia aprendizagem baseada em formação } \\
\text { conceitual sólida e universal }\end{array}$ & $\begin{array}{l}\text { Propicia aprendizagem baseada na prática } \\
\text { dos negócios }\end{array}$ \\
\hline Pertence ao sistema educacional formal & Pertence ao sistema de gestão da empresa \\
\hline Transmite crenças e valores universais da & Transmite crenças e valores da empresa e de \\
sociedade & seu ambiente de negócios \\
\hline Desenvolve a cultura acadêmica & Desenvolve a cultura empresarial \\
\hline Forma cidadãos competentes para gerar o & Forma cidadãos competentes para gerar o \\
sucesso das instituições e da comunidade & sucesso da empresa e dos clientes \\
\hline
\end{tabular}

Fonte: Adaptado de Eboli (2004, p.202)

\subsubsection{Sustentabilidade}

"Ser um centro gerador de resultados para a empresa, buscando sempre agregar valor ao negócio. Pode significar também buscar fontes alternativas de recursos que permitam um orçamento próprio e autossustentável. " (EBOLI, 2004, p.201)

A autora afirma que, no Brasil, percebe-se uma ineficácia no programa de UC e, aliado ao estreitamento da competitividade e a crise econômica, trouxeram uma preocupação para as empresas quanto ao investimento feito na UC, pois elas não querem desperdiçar recursos com programas que não sejam rentáveis, ou que não se possa mensurar essa rentabilidade. 
Segundo Eboli (2004), um dos maiores desafios que as empresas enfrentam é a criação de indicadores que mensurem de verdade os resultados dos investimentos em treinamentos. Os indicadores atuais abordam fatores como quantidade de dias de treinamento, horas de treinamento/funcionário, média de custo e etc, não mostrando o real impacto do treinamento no negócio.

Eboli (2004) propõe que esses indicadores sejam pautados na mensuração da qualidade dos produtos e serviços, aumento do marketshare, melhoria na qualidade do atendimento, melhoria na imagem da empresa, recebimento de prêmios, aumento da carteira de produtos, novos negócios, tornar-se referência de mercado.

Em paralelo ao sistema de avaliação dos treinamentos, que será tratado de forma mais aprofundada na sequênca, a autora aborda a auto sustentabilidade, ou seja, a importância de haver um orçamento próprio para uma UC e a possibilidade de sua transformação em um centro de resultados. Buscar esses fatores é uma postura recomendável, visto que não torna a UC refém do orçamento da empresa.

Sintetizando esses sete princípios, Eboli afirma que:

Um programa de treinamento é mais bem-sucedido quando os participantes corretos (seleção) recebem conhecimentos, habilidades e atitudes corretos ensinados por métodos, meios e instrutores adequados (processo) no meio e local certos, de tal forma que atinjam ou superem as expectativas da organização (aprendem objetivos e desempenho voltados para resultados). (EBOLI, 2004, p.220)

\subsubsection{O desafio da avaliação de treinamentos}

No princípio de sustentabilidade citado por Eboli (2004), é tratado um tema que, segundo a autora, é desafiador em uma UC: a avaliação dos treinamentos em educação corporativa.

Eboli, tendo como base os autores Scot Parry e Donald Kirkpatrik, afirma que a avaliação deve ocorrer em três (3) etapas e quatro (4) níveis, conforme descritos abaixo:

\section{- 19a etapa: Avaliação antes do treinamento}

Segundo a autora, a avaliação deve começar verificando as necessidades que antecedem o treinamento, tendo o propósito de minimizar a 
lacuna entre o início e o fim do treinamento, no que diz respeito ao comportamento do aluno.

É importante que algumas questões sejam abordadas como qual a necessidade de aprendizado dos participantes, quais as competências requeridas a eles, o que no ambiente profissional irá sustentar o desempenho desejado, quais os recursos facilitadores de aprendizagem e etc.

Eboli (2004) afirma que as respostas a essas questões devem nortear o desenvolvimento do programa de treinamento. Faz-se necessário também o desenvolvimento de estratégias para agregar essas competências ao ambiente de trabalho, visto que muitos problemas de desempenho não são solucionados apenas com treinamentos.

\section{- 2a etapa: Avaliação durante o treinamento}

Segundo Eboli (2004), uma avaliação durante o treinamento é essencial para que ocorram correções pontuais necessárias durante o processo. Deve-se verificar a satisfação com as condições de aprendizagem, se os participantes estão absorvendo o conteúdo ministrado e qual a relevância desse conteúdo e se os participantes aproveitam sua própria experiência.

\section{- 3a etapa: Avaliação depois do treinamento}

Essa avaliação tem o intuito de aferir se, mesmo após o passar do tempo e com as adversidades da rotina de trabalho, o funcionário consegue aplicar tudo o que aprendeu.

Segundo a autora, alguns fatores devem ser analisados como o que ajuda ou dificulta o desempenho do profissional, o que pode ser feito para melhorar o que ajuda e eliminar o que atrapalha, quais os aspectos do treinamento foram mais ou menos importantes, mudanças no comportamento pré e pós treinamento e resultados financeiros.

A avaliação depois do treinamento está estruturada em 4 níveis:

\section{- $1^{\text {a }}$ nível de avaliação: Reação}

Sendo, segundo Eboli (2004), uma prática bem comum e sem maiores problemas para a empresa, a avaliação de reação é feita através de um questionário que busca aferir qual a opinião dos treinandos em relação a assuntos como conteúdo, matérias e instrutores. 
- 2 ${ }^{a}$ nível de avaliação: Aprendizado

Segundo a autora, avaliar aprendizado quer dizer mensurar o nível de aumento do conhecimento, habilidades e atitudes após serem submetidos ao treinamento.

\section{- 3a nível de avaliação: Aplicação}

Eboli afirma que avaliar aplicação significa identificar se os funcionários estão utilizando do conteúdo aprendizado para mudar seu comportamento no trabalho, ou seja, esse nível avalia sua performance na rotina de trabalho.

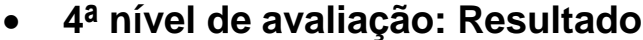

Segundo Eboli, avaliar resultado significa analisar o retorno que esse treinamento trouxe para a empresa, afetando de modo positivo ou negativo seus indicadores.

Avaliar os resultados obtidos com treinamento, considerando-se esses quatro níveis, implica planejar e integrar too processo de avaliação para ter clareza da informação (o quê?) que se pretende levantar, em qual fonte (onde?), por meio de qual método (como?) e em que momento (quando?). (EBOLI, 2004, p.224) 


\section{Métodos e procedimentos de coleta e de análise de dados do estudo}

Este capítulo apresenta a metodologia de pesquisa utilizada, bem como o tipo de pesquisa e suas fontes de informação. Aborda também o método e o procedimento da coleta de dados, além do tratamento desses dados e as limitações encontradas durante a pesquisa.

\subsection{Etapas de coleta de dados e fontes de informação}

Segundo Vergara (2004), ao se fazer um estudo, deve ser informado qual tipo de pesquisa será realizada quanto aos fins e aos meios. Quanto aos fins, foi descritiva, pois teve como foco identificar a atuação da UniAzul considerando os sete princípios de Eboli (2004).

Já em relação aos meios de investigação, foi feito um estudo de caso com foco no sistema de educação corporativa da Azul Linhas Aéreas; houve também uma pesquisa bibliográfica, pois foram utilizados artigos e livros que tratam sobre o assunto; pesquisa documental, pois foram consultados manuais da própria empresa; pesquisa participante e de campo, pois o pesquisador faz parte do quadro de funcionários da empresa, realizou entrevistas e aplicou um questionário.

Ainda segundo Vergara (2004), podem ser utilizadas amostras probabilísticas e não probabilísticas. As informações foram coletadas por meio de entrevistas e questionários. Nas entrevistas foi utilizado o critério de amostra não probabilísticas de tipicidade, pois os elementos escolhidos são considerados representantes da população-alvo.

Primeiramente, houve uma tentativa de realizar entrevistas com os agentes de atendimento que fazem parte do Projeto Multiplicador, funcionando como uma extensão da UniAzul em seu local de trabalho, adquirindo conhecimento em manuais e treinamentos e compartilhando com os demais colegas de trabalho. Porém, após envio do roteiro da entrevista, apenas uma agente de atendimento se disponibilizou para ser entrevistado. Esta será mencionada como Multiplicadora a partir daqui. O roteiro dessa entrevista encontra-se no Apêndice 3. 
O questionário foi aplicado em ocupantes do cargo de agente de atendimento e foi estruturado em duas sessões. A primeira, com quatro perguntas, com o objetivo de buscar informações como tempo de empresa e o nível de conhecimento em relação à UniAzul, e a segunda sessão, com 20 perguntas, com o objetivo de relacionar os princípios de Eboli (2004) com o serviço prestado pela UniAzul.

O questionário foi enviado para todos os 80 agentes de atendimento do Aeroporto Santos Dumont (SDU) e obteve-se 26 respostas. As perguntas do questionário encontram-se no Apêndice 1 desse estudo.

Para que o estudo alcançasse uma maior riqueza de informações, houve uma tentativa de entrevistar os supervisores do SDU, porém, após um contato inicial para explicar o objetivo do trabalho, foi solicitado o envio do roteiro por email. Após esse envio o roteiro foi respondido de forma direta por um dos supervisores que não se disponibilizou a prestar nenhum esclarecimento sobre o que respondeu, mesmo após várias tentativas. As perguntas utilizadas encontram-se no Apêndice 2 desse estudo.

Foi realizada uma entrevista com uma representante da UniAzul, também considerando o critério de tipicidade. Sempre que forem feitas referências a ela será utilizada a denominação UNI. O roteiro de entrevista, estruturada em 11 perguntas, encontra-se no Apêndice 4.

\subsection{Procedimentos e instrumentos de coleta de dados}

Primeiramente foram coletadas informações em artigos e livros que abordam o tema educação corporativa. Após isso, documentos internos da empresa, disponíveis na intranet, foram estudados.

O roteiro das entrevistas e o questionário foram elaborados com base Pereira et al. (2006) e Dias (2008) e, como já informado, seguem nos Apêndices $1,2,3$ e 4.

O questionário teve como objetivo avaliar, considerando a opinião dos agentes de atendimento, a atuação da Uniazul com base nos princípios de Eboli (2004). Sobre as entrevistas, foram realizadas duas: Com a Multiplicadora, com o objetivo buscar uma melhor percepção sobre a relação entre a UC e os princípios já citados, e com a UNI, para saber a visão dela sobre como a UniAzul se comporta em relação aos princípios de Eboli (2004).

O supervisor respondeu às perguntas do roteiro da entrevista através do email previamente enviado. 
Os entrevistados e os respondentes foram informados sobre o sigilo da pesquisa.

\subsection{Formas de tratamento e análise dos dados coletados para o estudo}

A análise dos dados coletados foi feita considerado o referencial teórico. As entrevistas e questionários foram analisadas de maneira qualitativa, sintetizando as respostas em busca de opiniões convergentes entre os respondentes e salientando as divergentes, sempre relacionando aos princípios de Eboli (2004).

\subsection{Limitações do Estudo}

Durante o estudo podem ter havido algumas limitações como possível desinteresse dos funcionários em responder o questionário; receio dos entrevistados ao falar sobre a empresa; interpretação enviesada dos resultados por conta de o pesquisador fazer parte do quadro de funcionários da empresa e dificuldades em conseguir entrevistas presenciais.

Mesmo com essas limitações considera-se o estudo como válido, visto que gerou informações relevantes para o atingimento do objetivo final especificado. 


\section{Apresentação e análise dos resultados}

Este capítulo descreve e analisa os resultados obtidos após a coleta de dados, bem como apresenta dados relevantes sobre a empresa.

\subsection{A Empresa}

A Azul Linhas Aéreas, companhia aérea formada após a fusão entre a Azul Linhas Aéreas Brasileiras e a Trip Linhas Aéreas é, segundo informa o seu site, a terceira maior companhia aérea do país. Com uma frota de 134 aeronaves, mais de 10.000 funcionários, 860 voos diários, 104 destinos servidos e 30\% do total de decolagens do país, a Azul consolida-se como a terceira maior companhia aérea do país.

Fundada em 2008, a empresa já recebeu diversos reconhecimentos nacionais e internacionais por seus serviços. Em 2017, a Skytrax World Airline Awards elegeu-a como bicampeã na categoria "Melhor companhia aérea lowcost (baixo custo) da América do Sul". Pelo segundo ano consecutivo, a Azul ganhou os títulos de "Melhor companhia aérea low-cost do mundo", concedido pelo CAPA - Centre for Aviation, bem como a categoria de "Melhor Empresa Aérea do Brasil" pela publicação Viagem e Turismo.

A universidade corporativa da Azul Linhas Aéreas, a UniAzul, situa-se em Campinas, no estado de São Paulo, e tem como finalidade a formação e aperfeiçoamento de todos funcionários e terceiros, de acordo com as diretrizes da empresa.

Criada em 2008, a UniAzul é considerada hoje o mais amplo centro de treinamento de profissionais do setor em toda a América Latina.

Fornece cursos que contemplam todas as áreas da empresa, onde os funcionários têm a oportunidade de, por muitas vezes, fazer sua primeira viagem de avião ao ir para a UniAzul, o que já cria uma identidade positiva com a empresa.

A UniAzul conta com ambientes que recriam os processos de manutenção de aeronaves, cabine de bordo e até balcões de check-in, com o objetivo conferir segurança às operações, que é o principal valor da empresa. 
Com o lema "nós servimos a quem serve", conforme citado em seu manual, a UniAzul realiza um trabalho alinhado às necessidades das áreas da Azul e, ao mesmo tempo, em conformidade com as agências reguladoras.

Além de atender toda a Azul no tocante à educação corporativa, a UniAzul também é responsável pela editoração, publicação e disponibilização de todas as publicações, manuais e documentos técnicos da companhia.

Por ser estruturada à semelhança de uma universidade, a UniAzul é composta por 10 faculdades que abrangem todas as áreas da Azul, além de uma Secretaria, áreas de Treinamento e Desenvolvimento Organizacional e também por Publicações Corporativas, que é a biblioteca da Azul.

John Rodgerson, presidente da Azul citou, em uma entrevista para a revista de bordo Azul Magazine, que a UniAzul é responsável por disseminar um dos principais pilares da Azul, chamado de OPA - Observe, Perceba e Atenda.

Os funcionários são treinados para observar quais as necessidades e desejos do cliente, perceber e prestar atenção ao perfil de cada um e atender com atenção verdadeira e simpatia genuína. (RODGERSON, 2018, p. 2)

Já Roberto Hobeika, diretor de Serviço ao Cliente e Recursos Humanos da Azul, citou, em 2016, em um artigo do site da Azul que:

A UniAzul tem o compromisso de manter todos nossos profissionais preparados para exercerem suas atividades com a mais alta capacidade técnica, cumprindo, dessa forma, o compromisso de excelência na prestação de serviço aos nossos Clientes. No entanto, o papel da nossa universidade não para por aí. Temos diariamente a responsabilidade de perpetuar a Cultura Azul, além da integração das pessoas que passam pelos cursos presenciais.(HOBEIKA, 2016, p.01)

\subsection{Descrição e Análise dos resultados}

Na sequência serão detalhados os conteúdos dos questionários aplicados aos agentes de atendimento e das entrevistas realizadas com o supervisor, a Multiplicadora e a UNI.

Os respondentes do questionário, em sua maioria, possuem entre 3 e 5 anos de empresa, conforme a figura 3, e já visitaram à UniAzul para cursos por mais de 3 vezes, conforme a figura 4 . 
Figura 4 - Tempo de empresa dos respondentes do questionário

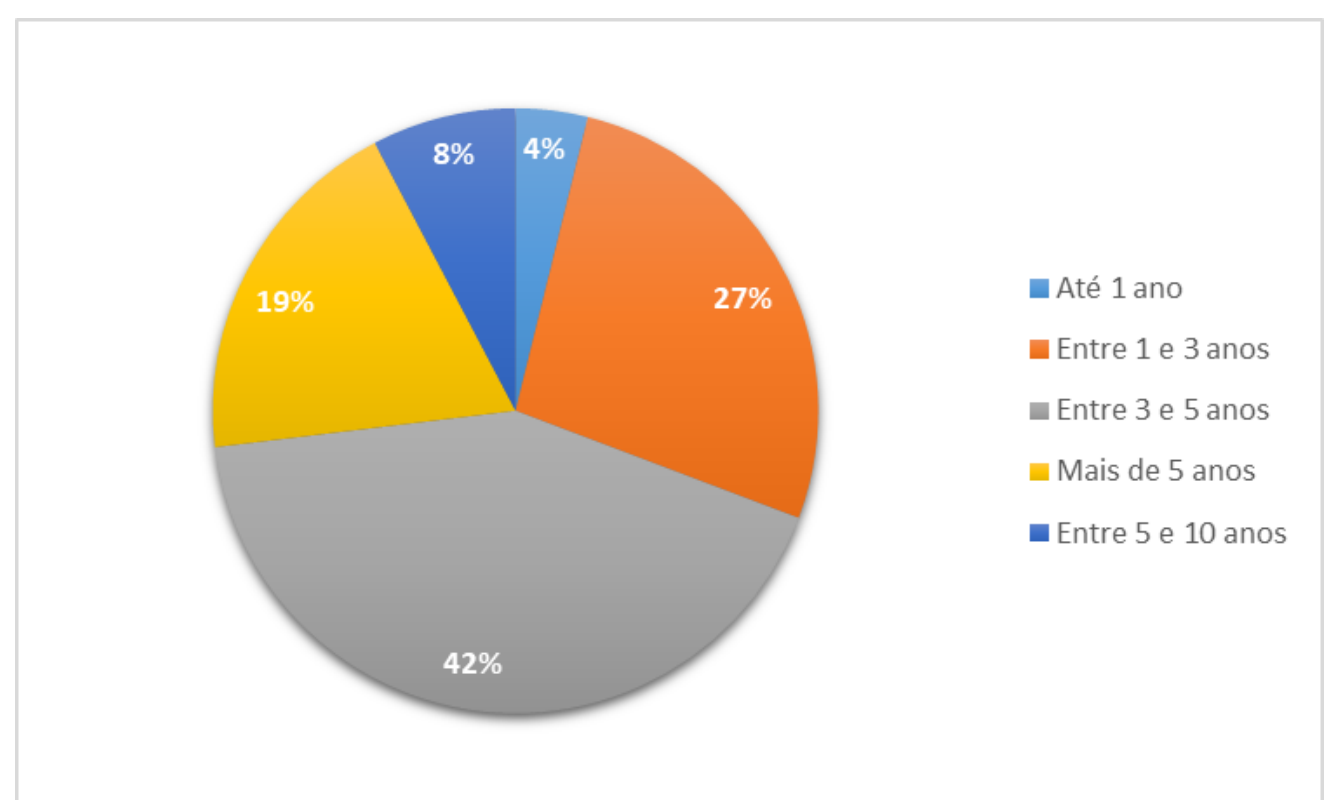

Fonte: Próprio autor (2018)

\section{Figura 5 - Quantidade de visitas à UniAzul}

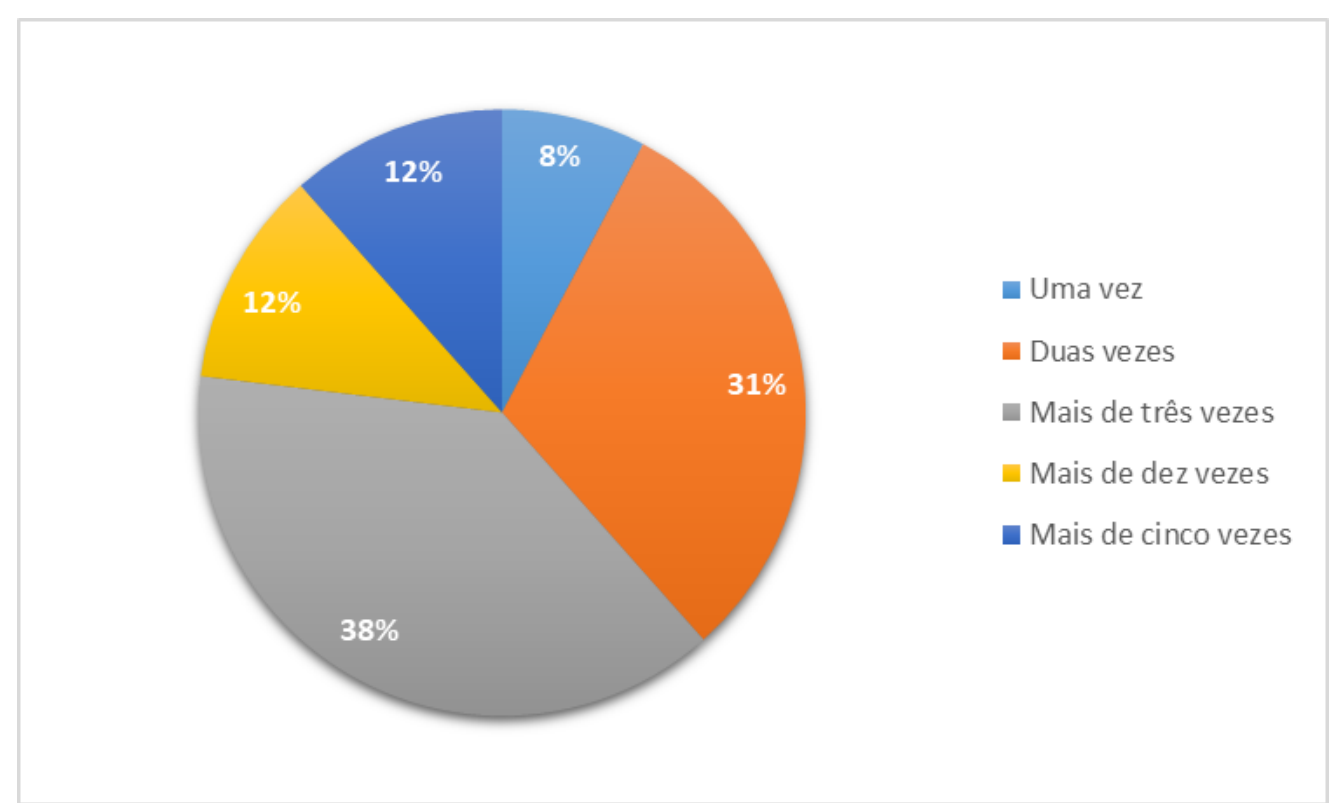

Fonte: Próprio autor (2018)

Com relação aos entrevistados, as informações encontram-se na tabela 1.

\section{Tabela 1- Dados dos entrevistados}

\begin{tabular}{|c|c|c|}
\hline & Tempo de Empresa & Quantidade de visitas à UniAzul \\
\hline Supervisor & 10 anos & mais de dez vezes \\
\hline Multiplicadora & 5 anos & mais de dez vezes \\
\hline UNI & 10 anos & (é o seu local de trabalho) \\
\hline
\end{tabular}

Fonte: Próprio autor (2018) 


\subsubsection{Análise dos resultados}

Esse estudo teve como objetivo principal identificar e analisar, com base na opinião dos funcionários do setor de Aeroportos, como é percebida a atuação da UniAzul, considerando os sete princípios norteadores para o sucesso de um sistema de educação corporativa, propostos por Eboli (2004), que são: Competitividade, Perpetuidade, Conectividade, Disponibilidade, Cidadania, Parceria e Sustentabilidade.

A análise dos dados foi feita considerando as respostas do questionário e o conteúdo das entrevistas, unindo a visão dos gestores com a dos agentes de atendimento sobre o assunto. Também foi feito um paralelo com as respostas da UNI, com o intuito de verificar o alinhamento entre o discurso da UC e a percepção de seus clientes (gestores e funcionários da Azul).

Os dados foram complementados com as informações disponibilizadas em documentos internos, como o Manual Geral da UniAzul (MGU), disponível na intranet.

Em relação a análise do questionário, somou-se as respostas "concordo plenamente" com "concordo" e "discordo plenamente" com "discordo", gerando os graus "Concordo" e "Discordo", respectivamente.

Na sequência serão apresentadas as informações coletadas em relação aos princípios norteadores para o sucesso de uma UC.

\section{- Competitividade:}

Tabela 2 - Resultado das perguntas sobre Competitividade

\begin{tabular}{|l|c|c|}
\hline \multicolumn{1}{|c|}{ Perguntas } & Concordo & Discordo \\
\hline $\begin{array}{l}\text { A UniAzul me motiva a me comprometer com os objetivos } \\
\text { estratégicos da Azul }\end{array}$ & $96 \%$ & $4 \%$ \\
\hline Sou responsável pelo meu autodesenvolvimento & $100 \%$ & $0 \%$ \\
\hline A UniAzul motiva meu crescimento na Azul & $85 \%$ & $15 \%$ \\
\hline $\begin{array}{l}\text { A UniAzul me motiva a ser responsável pelo meu } \\
\text { autodesenvolvimento }\end{array}$ & $92 \%$ & $8 \%$ \\
\hline $\begin{array}{l}\text { Me sinto apto a realizar minhas funções após um treinamento } \\
\text { da UniAzul }\end{array}$ & $96 \%$ & $4 \%$ \\
\hline
\end{tabular}

Fonte: Próprio autor (2018) 
Segundo Eboli (2004) uma UC deve “(...) valorizar a educação como forma de desenvolver o capital intelectual dos colaboradores, transformando-os efetivamente em fator de diferenciação da empresa diante dos concorrentes, ampliando assim sua capacidade de competir. " (EBOLI, 2004, p.85)

Em média, 92\% dos respondentes percebem o princípio de Competitividade nas ações da UniAzul, ou seja, que ela desenvolve o seu capital intelectual, o que se transforma em vantagem competitiva diante da concorrência.

A UNI afirma que "o objetivo da UniAzul é que os funcionários saiam dos treinamentos com energia suficiente para encantar os clientes, e isso é uma grande vantagem competitiva".

Houve unanimidade no quesito autodesenvolvimento. Todos os respondentes e entrevistados informaram que são responsáveis pelo seu autodesenvolvimento e que a UniAzul os motiva a isso.

O supervisor, ao ser questionado sobre o assunto afirma que "o interesse em crescimento/desenvolvimento deve ser compartilhado entre a empresa e o tripulante"

A Multiplicadora afirma que a UniAzul poderia contribuir mais para 0 crescimento dos funcionários na Azul com a inclusão de cursos eletivos, onde não há necessidade de uma demanda dos gestores ou da própria UniAzul para se fazer um curso. Esses cursos desenvolveriam as competências essenciais de nível humano, ou seja, competências individuais para que haja êxito nos objetivos estratégicos, conforme cita Eboli (2004). No questionário essa pergunta foi a que teve o maior índice de insatisfação, com 15\%.

Pelas informações coletadas pode-se dizer que é percebido o princípio de competitividade nas práticas da UniAzul, uma vez que seu foco está em desenvolver o capital intelectual dos funcionários através de seus cursos.

\section{- Perpetuidade:}

Tabela 3 - Resultado das perguntas sobre Perpetuidade

\begin{tabular}{|l|c|c|}
\hline \multicolumn{1}{|c|}{ Perguntas } & Concordo & Discordo \\
\hline A UniAzul dissemina a cultura organizacional da Azul & $96 \%$ & $4 \%$ \\
\hline A UniAzul fortalece a missão, visão e valores da Azul & $100 \%$ & $0 \%$ \\
\hline
\end{tabular}

Fonte: Próprio autor (2018) 
Para Eboli (2004) uma UC não deve apenas ensinar, mas também tem o dever de transmitir e perpetuar a cultura da empresa.

Nos resultados obtidos, uma média de $98 \%$ de respostas positivas, pôde-se encontrar características que mostram que a UniAzul é uma ferramenta de disseminação da cultura da Azul, através de cursos que promovem esse fato. Eboli (2004) afirma a importância do princípio da perpetuidade complementando que a educação é importante não só para desenvolver o potencial de cada colaborador, mas também perpetuar existência da empresa.

O supervisor entrevistado afirma que no treinamento inicial para Aeroportos essa cultura é muito disseminada, pois há um contato direto com os diretores da Azul, onde são repassados os valores da empresa. A Multiplicadora citou que "o ambiente da UniAzul propicia essa disseminação".

A UNI cita um dos módulos do curso inicial, o "Bem-Vindo a Bordo" onde os funcionários que acabaram de entrar na empresa têm contato direto com toda a diretoria da Azul, podendo fazer perguntas e conhecer mais sobre os valores da Azul. Tem como objetivo integrar os novos colaboradores à cultura da organização, o que ela oferece aos seus funcionários, bem como seus deveres em relação às diretrizes organizacionais.

Pode-se dizer então que é percebido o princípio de perpetuidade nas práticas da UniAzul, pois a mesma foi identificada como uma ferramenta de transmissão e perpetuação da cultura da Azul, seguindo o princípio proposto por Eboli (2004).

\section{- Conectividade:}

Tabela 4 - Resultado das perguntas sobre Conectividade

\begin{tabular}{|l|c|c|}
\hline \multicolumn{1}{|c|}{ Perguntas } & Concordo & Discordo \\
\hline A UniAzul me motiva a compartilhar meus conhecimentos & $92 \%$ & $8 \%$ \\
\hline A UniAzul me motiva a treinar novos contratados & $73 \%$ & $27 \%$ \\
\hline
\end{tabular}

Fonte: Próprio autor (2018)

Eboli (2004) afirma que "a UC é um processo e uma mentalidade que permeiam toda a organização e deve estimular as pessoas a compartilhar os 
conhecimentos considerados críticos para o negócio da empresa" (EBOLI, 2004, p. 129).

No questionário, 92\% dos respondentes se mostram motivados pela UniAzul a compartilhar seus conhecimentos, e $27 \%$ dos respondentes não se sentem motivados a treinar novos contratados, havendo um contraste entre compartilhar conhecimentos e treinar novos contratados.

Sobre treinar novos contratados, o supervisor entrevistado cita o "Projeto Multiplicador", que já foi explicado no tópico 3.1 desse estudo, onde existe uma ação da UniAzul para que funcionários compartilhem seus conhecimentos e auxiliem novos contratados.

Já a Multiplicadora cita que "em todos os treinamentos realizados na UniAzul, eles colocam como principal objetivo que, ao chegarmos em nossa base, os procedimentos sejam multiplicados para a equipe."

A UNI reforçou a importância da sinergia entre os funcionários e o compartilhamento de experiências entre eles durante os treinamentos, citando também a ação do Projeto Multiplicador.

Analisando as informações obtidas, pode-se perceber que a UniAzul cumpre o princípio de conectividade, porém há uma certa divergência entre os respondentes pois, segundo Eboli (2004), a empresa como um todo deve ter influência na geração e transferência de conhecimento no processo de aprendizagem organizacional.

\section{- Disponibilidade:}

Tabela 5 - Resultado das perguntas sobre Disponibilidade

\begin{tabular}{|l|c|c|}
\hline \multicolumn{1}{|c|}{ Perguntas } & Concordo & Discordo \\
\hline $\begin{array}{l}\text { O EAD da UniAzul é importante para meu aprendizado na } \\
\text { Azul }\end{array}$ & $65 \%$ & $35 \%$ \\
\hline E estrutura física da UniAzul facilita minha aprendizagem & $100 \%$ & $0 \%$ \\
\hline
\end{tabular}

Fonte: Próprio autor (2018)

Eboli (2004) afirma que esse princípio se refere à disponibilidade de atividades e recursos educacionais de fácil uso e acesso, gerando condições favoráveis de aprendizagem a qualquer hora e em qualquer lugar. 
Todos os respondentes estão satisfeitos com a estrutura física e tecnológica da UniAzul, e que esse é um fator contribuinte para o aprendizado, com média de $83 \%$ de respostas positivas.

Em relação ao EAD, que, segundo Meister (1999), é um exemplo de tecnologia aceleradora de aprendizado, 35\% dos respondentes não percebem sua importância no aprendizado na Azul. Ao ser questionado sobre a sua opinião em relação ao EAD, o supervisor responde que é muito bom, mas não quis se aprofundar na resposta.

Eboli (2004) afirma que o sucesso de uma UC passa pela fundamentação no EAD e no uso intenso de tecnologia em diversos formatos, contudo, a Multiplicadora não se mostrou muito favorável ao seu uso, visto que compromete a qualidade do ensino. Segundo ela, o EAD é "um mal necessário", pois perde o que a UniAzul tem de melhor que é o relacionamento interpessoal durante os treinamentos presenciais, conforme visto no princípio citado anteriormente, onde mostra que há uma motivação da UniAzul no compartilhar de seus conhecimentos durante os treinamentos, criando uma sinergia entre os funcionários. A questão da sinergia citada pela multiplicadora também é identificada no princípio de cidadania.

A UNI acredita que o uso do EAD é válido por conta dos recursos economizados com transporte e hotel além de não comprometer a produtividade pois evita viagens frequentes a Campinas. Ela afirma, porém, que para se ter um EAD eficiente é necessário o apoio do gestor, algo que não acontece com frequência, como será visto no princípio de parceria.

Considerando o que Eboli (2004) propõe para o princípio de disponibilidade, os achados da pesquisa indicam que a UniAzul provê uma educação de fácil uso e acesso, porém enfrenta um desafio na implantação do EAD e sua aceitação por parte dos funcionários e gestores, como pôde ser percebido no relato da Multiplicadora, a qual tem um papel fundamental na disseminação dos conhecimentos da UniAzul na área em que atua. 
- Cidadania:

Tabela 6 - Resultado da pergunta sobre Cidadania

\begin{tabular}{|l|c|c|}
\hline \multicolumn{1}{|c|}{ Perguntas } & Concordo & Discordo \\
\hline $\begin{array}{l}\text { As ações da UniAzul incentivam a construção de um } \\
\text { relacionamento saudável entre os colaboradores, } \\
\text { concorrentes e fornecedores }\end{array}$ & $96 \%$ & $4 \%$ \\
\hline
\end{tabular}

Fonte: Próprio autor (2018)

Segundo Eboli (2004) esse princípio visa estimular a cidadania individual e corporativa, formando pessoas capazes de refletir sobre a realidade da empresa, com bases éticas, e modificá-las, se necessário.

Conforme a tabela $6,96 \%$ dos respondentes estão satisfeitos com as iniciativas da UniAzul em relação a esse princípio.

Em relação a esse assunto, o supervisor citou a importância do curso Corporate Resource Management (CRM) que, conforme consta no MGU, possui como objetivo a aplicação dos princípios e conceitos de fatores humanos para o melhoramento do desempenho das equipes de funcionários da Azul, a partir do aprimoramento da interação entre os diferentes setores, departamentos e profissionais da organização buscando o aumento dos indicadores de desempenho da segurança operacional (IDSO).

A Multiplicadora foi questionada sobre como a UniAzul facilita a integração entre as áreas da Azul e ela informou que nos cursos presenciais há uma integração entre os funcionários e que o ambiente descontraído da UniAzul propicia essa integração, onde cada funcionário pode compartilhar sua visão sobre a empresa. Citou ainda que a UniAzul não tem qualquer influência na relação com o meio externo da Azul.

Para a UNI essa cidadania se dá através dos cursos presenciais, com funcionários de vários cargos e regiões diferentes, compartilhando suas experiências e percepções sobre a empresa, gerando um relacionamento saudável entre eles.

Ela também cita o CRM, que, segundo ela, visa garantir a contínua incorporação da filosofia operacional da Azul e a disseminação dos seus princípios em toda a empresa.

Foi identificado que a UniAzul atua com sucesso no fomento da cidadania para os funcionários da organização, porém não foram encontradas ações que 
mostrem um incentivo a um bom relacionamento com a concorrência. Segundo Eboli (2004), as empresas são estimuladas a ter uma postura firme e inovadora diante de assuntos éticos e de responsabilidade social, visando melhorar a qualidade da relação empresa-sociedade.

- Parceria:

Tabela 7 - Resultado das perguntas sobre Parceria

\begin{tabular}{|l|c|c|}
\hline \multicolumn{1}{|c|}{ Perguntas } & Concordo & Discordo \\
\hline Meus gestores têm muita influência na minha aprendizagem & $81 \%$ & $19 \%$ \\
\hline $\begin{array}{l}\text { Meus gestores me motivam a participar dos programas de } \\
\text { treinamento da UniAzul }\end{array}$ & $69 \%$ & $31 \%$ \\
\hline A UniAzul possui parceria com outras instituições de ensino & $0 \%$ & $100 \%$ \\
\hline
\end{tabular}

Fonte: Próprio autor (2018)

Para Eboli (2004) desenvolver continuamente as competências dos colaboradores é uma tarefa complexa, e para isso, faz-se necessário o estabelecimento de parcerias internas (com líderes e gestores) e externas (instituições de nível superior).

Em média, 50\% das respostas foram positivas em relação a esse princípio, porém foi possível perceber uma discrepância entre a fala do supervisor e a resposta dos seus funcionários, pois o supervisor entrevistado reconheceu seu papel no aprendizado de seus funcionários, citando que seu cargo "funciona como um braço da UniAzul após o treinamento inicial, sobretudo no difundir da cultura e na segurança operacional. " A Multiplicadora, ao ser questionada sobre os gestores motivarem a participação nos cursos presenciais de capacitação da UniAzul, ela cita que os mesmos têm dificuldades nesse aspecto por conta do comprometimento da escala de trabalho. Essa informação também foi encontrada na segunda pergunta apresentada na tabela 7 que obteve um nível de insatisfação de $31 \%$.

A Multiplicadora cita ainda que os gestores dão aos funcionários autonomia na tomada de decisão, e isso influencia, segundo ela, em sua aprendizagem.

A UNI afirma que o papel do gestor é de suma importância para o êxito da UniAzul, incentivando os funcionários a realizar os cursos necessários para seu crescimento. 
Um ponto de atenção é que $100 \%$ dos respondentes do questionário e os entrevistados informam que a UniAzul não possui parceria com outras instituições. A Multiplicadora se mostrou interessada em parcerias com escolas de aviação e o supervisor informou que seria importante haver acordos com outros cursos.

Pode-se afirmar então que, na visão dos funcionários, não há uma percepção de uma atuação completa em relação ao princípio de parceria, visto que, segundo Eboli (2004), esse princípio envolve parceria interna, relação entre líderes e gestores, a fim de que se responsabilizem pelo desenvolvimento dos funcionários; e parceria externa, onde há acordos com universidades e instituições de ensino superior. $O$ item parceria externa aparenta ser um ponto de melhoria, segundo os pesquisados.

\section{- Sustentabilidade:}

Tabela 8 - Resultado das perguntas sobre Sustentabilidade

\begin{tabular}{|l|c|c|}
\hline \multicolumn{1}{|c|}{ Perguntas } & Concordo & Discordo \\
\hline A UniAzul está diretamente ligada aos resultados da Azul & $96 \%$ & $4 \%$ \\
\hline $\begin{array}{l}\text { O feedback que recebo após os treinamentos da UniAzul são } \\
\text { satisfatórios }\end{array}$ & $42 \%$ & $58 \%$ \\
\hline $\begin{array}{l}\text { O acompanhamento da UniAzul pós treinamento foi } \\
\text { satisfatório }\end{array}$ & $38 \%$ & $62 \%$ \\
\hline
\end{tabular}

Fonte: Próprio autor (2018)

Segundo Eboli (2004) a UC deve ser um centro que gere resultados para a empresa e busque agregar valor ao negócio, buscando fontes alternativas de recursos que permitam um orçamento autossustentável. A autora inclui ainda, no princípio de sustentabilidade, a necessidade de se medir o serviço prestado pela UC, pois, segundo ela, é um desafio implantar esse sistema de avaliação.

Em média, 59\% das respostas a esse princípio foram positivas. Esse resultado é devido aos índices de insatisfação quanto ao feedback dado pela UniAzul, conforme mostra a tabela 8. Tanto o supervisor como a Multiplicadora informam que não há um feedback nem um acompanhamento da UniAzul após os treinamentos. O supervisor, ao ser questionado sobre isso, informa ser esse um ponto de atenção e que falta efetividade nesse aspecto. 
A UNI também afirma ser esse um ponto de melhoria a ser explorado pela UniAzul e que fatores como tempo e escala de trabalho dos instrutores dificultam tal ação.

Sobre esse assunto, no MGU foi encontrado que a UniAzul adota indicadores padronizados para mensurar seu desempenho. Esses indicadores estão classificados nas categorias: Financeiro, Produtividade e Satisfação/Favorabilidade, conforme mostra a figura 6.

Figura 6 - Indicadores de Desempenho UniAzul

\begin{tabular}{|l||l||l|}
\hline \multicolumn{1}{|c||}{ Financeiro } & \multicolumn{1}{|c|}{ Produtividade } & Satisfação/Favorabilidade \\
$\Rightarrow$ Valor Orçado $x$ Realizado & $\begin{array}{l}\text { Vagas de treinamento } \\
\text { solicitadas/ofertadas } x \\
\text { utilizadas } \\
\text { № de alunos treinados } \\
\text { № de alunos reprovados ou } \\
\text { em recuperação }\end{array}$ & $\Rightarrow \begin{array}{l}\text { Nível de } \\
\text { satisfação/favorabilidade }\end{array}$ \\
\hline
\end{tabular}

Fonte: Adaptado do Manual Geral da UniAzul (2018)

A UniAzul também analisa os indicadores da Azul para atestar a eficácia do seu trabalho, visto que, segundo a UNI, se o aluno absorveu de maneira satisfatória todo o conteúdo ministrado e desempenha um bom papel em sua área de atuação, a operação da Azul funcionará normalmente.

Segundo o modelo de avaliação citado por Eboli (2004) no princípio de sustentabilidade, a avaliação pós treinamento deveria ser realizada em quatro níveis: Reação, Aprendizado, Aplicação e Resultado.

As ações UniAzul mostram não estar de acordo com o terceiro nível de avaliação, o de Aplicação, por não possuir ferramentas próprias para mensurar se os treinamentos estão acrescentando algo em relação à prática de trabalho dos funcionários, fazendo com que mudem seu comportamento no dia a dia da operação.

Conforme o MGU é possível perceber que existe as avaliações de nível 1, 2 e, de certa forma, 4. O nível 1, reação, é medido através de uma avaliação de Reação, o nível 2, Aprendizado, por meio da aplcação de provas e o nível 4, Resultado, por meio de indicadores globais da Azul.

Sobre a relação da UniAzul com os resultados da Azul, 96\% dos respondentes afirmam que a UniAzul tem total influência no sucesso da Azul, e a 
Multiplicadora complementa afirmando que existe muita relação e "se não fosse a UniAzul, a Azul não teria a cultura que tem e nem seria quem é."

Em relação a ter um orçamento autossustentável, a UNI cita que receitas alternativas são geradas através da venda de treinamentos e locação de sua estrutura física e tecnológica, como salas de aula e simuladores de voo.

Identifica-se então que não são totalmente percebidos nas práticas da UniAzul o princípio de sustentabilidade, visto que há uma dificuldade na mensuração dos seus serviços pós treinamento. 


\section{Conclusões e recomendações para novos estudos}

O objetivo do estudo foi identificar e analisar a percepção dos empregados do setor de Aeroportos da Azul, sobre a atuação da UniAzul considerando os sete princípios norteadores para o sucesso de um sistema de educação corporativa propostos por Eboli (2004).

Para alcançar tal objetivo foram realizadas pesquisas bibliográfica, documental, de campo e estudo de caso.

O estudo foi limitado aos agentes de atendimento do SDU com a utilização de um questionário estruturado em 23 perguntas baseadas nos sete princípios já citados. Foram também realizadas entrevistas com um supervisor e com uma agente de atendimento participante do Projeto Multiplicador. Houve também uma entrevista com uma funcionária da UniAzul.

Ao todo, 26 funcionários responderam ao questionário e a análise das respostas foi feita mediante a elaboração de gráficos e tabelas que foram interpretadas de acordo com o referencial teórico apresentado.

Com base nas respostas do questionário, foram identificados quais princípios de Eboli (2004) são mais percebidos nas práticas da UniAzul.

Figura 7 - Presença dos princípios de Eboli (2004) na UniAzul

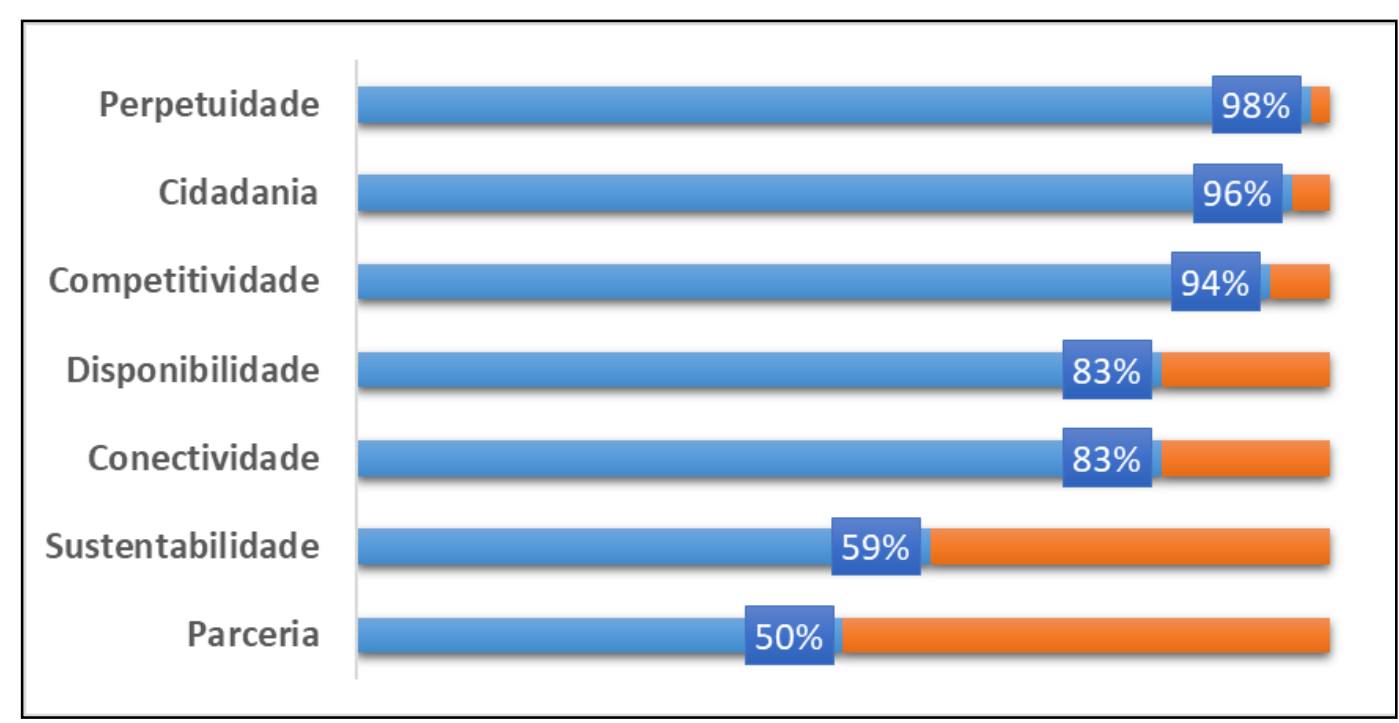

Fonte: Próprio autor (2018) 
De acordo com a figura 7, e considerando a análise dos resultados, podese concluir que todos os princípios de Eboli (2004) são percebidos nas ações da UniAzul, sendo o de perpetuidade o mais observado, tendo o maior índice de respostas positivas, por conta da forte disseminação da cultura e valores da Azul através de sua UC.

Os princípios de parceria e sustentabilidade são pontos de atenção, tendo o menor índice de respostas positivas, por conta da falta de acordos com outras instituições de ensino e pela falta de um acompanhamento pós treinamento.

\subsection{Sugestões e recomendações para novos estudos}

Sugere-se que seja investigado, na ótica de todos os funcionários da Azul, quais os princípios de Eboli (2004) são mais percebidos nas ações da UniAzul, através de entrevistas que atinjam todos os gestores e questionários que todos os funcionários tenham acesso para responder. Além disso, propõe-se comparar as práticas da UniAzul com outras UC's e apresentar os resultados desse novo estudo para a UniAzul, a fim de identificar a opinião da empresa sobre o assunto. 


\section{Referências Bibliográficas}

AZUL LINHAS AÉREAS. Manual Geral da UniAzul. Campinas, 2018 Disponível em: <intranet.voeazul.com.br> Acesso em: 12 de setembro. 2018

HOBEIKA, Roberto. UniAzul bate recorde em 2015 com 33 mil alunos treinados. Azul Linhas Aéreas, São Paulo, 06 abr. 2016. Disponível em: $<$ https://www.voeazul.com.br/imprensa/releases/UniAzul-bate-recorde-em-2015com-33-mil-alunos-treinados-1383357729212>. Acesso em: 27 de outubro de 2018.

BAYMA, F. Educação na era da Tecnologia da Informação e Comunicação. In: BAYMA, F. Educação Corporativa: Desenvolvendo e Gerenciando Competências. Volume 1, São Paulo: Pearson Prentice Hall, 2004

BOFF, L.A Educação na era da Tecnologia da Informação e Comunicação. In: BAYMA, F. Educação Corporativa: Desenvolvendo e Gerenciando Competências. Volume 1, São Paulo: Pearson Prentice Hall, 2004

DIAS; Mariana. Impacto do sistema de Educação Corporativa: Ferramenta de mensuração pós-implantação. 2008. 60 f. Trabalho de Conclusão de Curso (Especialização) - Programa de Pós-Graduação em Gestão de Pessoas, Universidade Federal do Rio Grande do Sul, Porto Alegre, 2008.

EBOLI, M. Educação Corporativa no Brasil: Da Prática à Teoria. In: XXXV Encontro da ANPAD, Rio de Janeiro: ANPAD, 2004

Verdades. São Paulo: Editora Gente, 2004

Educação Corporativa no Brasil: Mitos e

Metodologias de desenvolvimento de programas de Educação a Distância. In: BAYMA, F. Educação Corporativa: Desenvolvendo e Gerenciando Competências. Volume 1, São Paulo: Pearson Prentice Hall, 2004

Educação corporativa e desenvolvimento de competências. In: DUTRA JS; FLEURY, M. TL; RUAS, RL Competências: conceitos, métodos e experiências. São Paulo: Atlas, 2008

LOPES, N. Educação Corporativa: Estratégias de desenvolvimento e implementação de modelo. In: BAYMA, F. Educação Corporativa: Desenvolvendo e Gerenciando Competências. Volume 1, São Paulo: Pearson Prentice Hall, 2004

MEISTER, Jeanne C. Educação Corporativa: A gestão do Capital Intelectual através das Universidades Corporativas. Pearson Makron Books, São Paulo,1999 
PEREIRA, Carlos Eduardo et al. Educação corporativa e desenvolvimento de competências: um estudo de caso no setor de auditoria. In: ENANPAD Encontro Nacional dos Programas de Pós-Graduação em Administração, Salvador, 2006.

RODGERSON, J. A busca pela excelência. Azul Magazine, São Paulo: Azul Magazine, ed. 59, ano 5, p.2, março de 2018.

SANTOS, Jéssica Gomes. Avaliação de ações educacionais em Educação Corporativa: um estudo de caso na Universidade Petrobras. 2016. 81 f. TCC (Graduação) - Curso de Administração, Pontifícia Universidade Católica do Rio de Janeiro, Rio de Janeiro, 2016.

VERGARA, S.C. Projetos e relatórios de pesquisa em administração. 11. ed. São Paulo: Atlas, 2009. 


\section{Apêndice 1}

\section{Estudo de Caso UniAzul}

Olá, meu nome é Bruno Molinari e esta pesquisa faz parte do meu trabalho de conclusão de curso e tem como objetivo avaliar a influência da UniAzul em sua rotina de trabalho. Ela é de fácil e rápido preenchimento e seria importante poder contar com a sua participação. Não se preocupe! A pesquisa é totalmente anônima e será utilizada somente para fins didáticos.

*Obrigatório

1- Você conhece a UniAzul? *

- Sim

- Não

2- Quantos anos você tem de Azul? *

- Até 1 ano

- Entre 1 e 3 anos

- Entre 3 e 5 anos

- Mais de 5 anos

- Entre 5 e 10 anos

3- Quantas vezes já foi à UniAzul? *

- Nenhuma

- Nunca fui, só fiz EAD

- Uma vez

- Duas vezes

- Mais de três vezes

- Mais de cinco vezes

- Mais de dez vezes

4- Você sabia que a UniAzul possui cursos para áreas específicas em aeroportos? *

- Sim

- Não 
Peço que responda com sinceridade às perguntas abaixo, pois como já foi dito acima esse questionário é sigiloso.

5- A UniAzul me motiva a me comprometer com os objetivos estratégicos da Azul *

- Discordo Plenamente

- Discordo

- Concordo

- Concordo Plenamente

6- Sou responsável pelo meu autodesenvolvimento *

- Discordo Plenamente

- Discordo

- Concordo

- Concordo Plenamente

7- A UniAzul motiva meu crescimento na Azul *

- Discordo Plenamente

- Discordo

- Concordo

- Concordo Plenamente

8- A UniAzul me motiva a ser responsável pelo meu autodesenvolvimento *

- Discordo Plenamente

- Discordo

- Concordo

- Concordo Plenamente

9- A UniAzul dissemina a cultura organizacional da Azul *

- Discordo Plenamente

- Discordo

- Concordo

- Concordo Plenamente

10- A UniAzul fortalece a missão, visão e valores da Azul *

- Discordo Plenamente

- Discordo 
- Concordo

- Concordo Plenamente

11- A UniAzul me motiva a compartilhar meus conhecimentos *

- Discordo Plenamente

- Discordo

- Concordo

- Concordo Plenamente

12- A UniAzul me motiva a treinar novos contratados *

- Discordo Plenamente

- Discordo

- Concordo

- Concordo Plenamente

13- O EAD da UniAzul é importante para meu aprendizado na Azul *

- Discordo Plenamente

- Discordo

- Concordo

- Concordo Plenamente

14- E estrutura física da UniAzul facilita minha aprendizagem *

- Discordo Plenamente

- Discordo

- Concordo

- Concordo Plenamente

15- As ações da UniAzul incentivam a construção de um relacionamento saudável entre os colaboradores, concorrentes e fornecedores *

- Discordo Plenamente

- Discordo

- Concordo

- Concordo Plenamente 
16- Meus gestores tem muita influência na minha aprendizagem *

- Discordo Plenamente

- Discordo

- Concordo

- Concordo Plenamente

17- Meus gestores me motivam a participar dos programas de treinamento da UniAzul*

- Discordo Plenamente

- Discordo

- Concordo

- Concordo Plenamente

18- A UniAzul possui parceria com outras instituições de ensino *

- Discordo Plenamente

- Discordo

- Concordo

- Concordo Plenamente

19- A UniAzul está diretamente ligada aos resultados da Azul *

- Discordo Plenamente

- Discordo

- Concordo

- Concordo Plenamente

20- O feedback que recebo após os treinamentos da UniAzul são satisfatórios *

- Não recebi

- Discordo Plenamente

- Discordo

- Concordo

- Concordo Plenamente 
21- O acompanhamento da UniAzul pós treinamento foi satisfatório *

- Não recebi

- Discordo Plenamente

- Discordo

- Concordo

- Concordo Plenamente

22- Me sinto apto a realizar minhas funcões após um treinamento da UniAzul *

- Discordo Plenamente

- Discordo

- Concordo

- Concordo Plenamente

23- Utilize o espaço abaixo para qualquer esclarecimento e comentário que julgar se relevante 


\section{Apêndice 2}

\section{Entrevista Liderança}

1- Quantos anos você tem de Azul?

2- Quantas vezes já foi à UniAzul?

3- Você sabe quais cursos a UniAzul ministra com foco em aeroportos (limitação da pesquisa)?

4- Para você, qual o papel da UniAzul em relação a Azul? E em relação à capacitação de seus empregados?

5- Considerando os treinamentos que a UniAzul forneceu aos seus empregados $x$ outros treinamentos que eles tiveram na área, qual a relação percentual entre eles? Exemplo 50\% UniAzul e 50\% área

6- Você sabe qual o foco prioritário dos treinamentos da UniAzul?

7- Você consegue apresentar suas demandas de treinamento e ser atendido pela UniAzul?

8- Você acredita que seus funcionários se sentem mais aptos a realizar sua função após o treinamento da UniAzul?

9- Considerando os treinamentos que fez até hoje, qual o percentual deles que foi feito na UniAzul?

\section{- Competitividade}

10-Qual o papel da UniAzul no que diz respeito ao comprometimento do colaborador com os objetivos estratégicos da empresa?

11-Você acredita que o colaborador é responsável por buscar seu autodesenvolvimento? Qual o seu papel na busca por seu autodesenvolvimento? E qual o papel do seu colaborador?

\section{- Perpetuidade}

12- Como você percebe a atuação da UniAzul para a disseminação da cultura organizacional da empresa?

13- Qual o papel da UniAzul no fortalecimento da missão, visão e valores da Azul?

\section{- Conectividade}

14- Você percebe seus colaboradores e pares empenhados em compartilhar conhecimentos? Como?

15- Você percebe seus colaboradores empenhados em ajudar novos contratados após os treinamentos da UniAzul?

\section{- Disponibilidade}

16- Você enxerga algum avanço tecnológico nas aulas da UniAzul?

17- Qual sua opinião em relação ao EAD?

18- Para você, o ambiente da UniAzul facilita a aprendizagem? Como? 


\section{- Cidadania}

19- Como as ações da UniAzul incentivam a cidadania corporativa? (Capacidade de refletir criticamente sobre a realidade organizacional, de construí-la e modifica-la e de atuar pautados por postura ética e socialmente responsável)

20- Como a UniAzul facilita a integração entre as áreas da Azul, contribuindo para a construção de um relacionamento saudável entre as partes?

\section{- Parceria}

21- Como você vê a sua responsabilidade como gestor pela aprendizagem dos seus colaboradores?

22- Você conhece alguma parceria que a UniAzul possui com instituições de ensino? Seria importante ter?

\section{- Sustentabilidade}

23-Para você, qual a relação entre a UniAzul e os resultados da Azul?

24- Como a UniAzul agrega valor à Azul?

25- Como você enxerga o processo de avaliação dos treinamentos da UniAzul?

26- Como você vê o acompanhamento pós treinamento da UniAzul? 


\section{Apêndice 3}

\section{Entrevista Multiplicadores}

1- Quantos anos você tem de Azul?

2- Quantas vezes já foi à UniAzul?

3- Você sabe quais cursos a UniAzul ministra com foco em aeroportos (limitação da pesquisa)?

4- Para você, qual o papel da UniAzul em relação a Azul?

5- O quão satisfeito você está com a UniAzul?

6- Você se sente mais apto a realizar sua função após o treinamento da UniAzul?

\section{- Competitividade}

7- Você se considera uma pessoa preocupada com seu autodesenvolvimento? Como a UniAzul contribui para isso?

8- Como você enxerga que a UniAzul influencia no seu crescimento dentro da Azul?

\section{- Perpetuidade}

9- Como a UniAzul te motiva a manter seus conhecimentos atualizados?

10-Como você percebe que a cultura da Azul é disseminada nos treinamentos da UniAzul?

\section{- Conectividade}

11- Você é estimulado pela UniAzul para compartilhar seus conhecimentos com outros na rotina de trabalho e durante os treinamentos da UniAzul?

12- Você se sente motivado a adquirir conhecimento para treinar outros?

\section{- Disponibilidade}

13-Pra você, como o ambiente da UniAzul facilita a aprendizagem? 14- Qual sua opinião em relação ao EAD?

- Cidadania

15- Como a UniAzul te capacita a refletir criticamente sobre a realidade organizacional?

16- Como a UniAzul facilita a integração entre as áreas da Azul, contribuindo para a construção de um relacionamento saudável entre as partes? $\mathrm{E}$ com o meio externo?

\section{- Parceria}

17- Qual é o papel dos líderes em sua aprendizagem?

18- Os líderes te motivam a participar dos programas de treinamento da UniAzul? 
19-Você conhece alguma parceria que a UniAzul possui com instituições de ensino? Seria importante ter?

\section{- Sustentabilidade}

20- Para você, qual a relação entre a UniAzul e os resultados da Azul?

21- Como você foi avaliado nos treinamentos da UniAzul? O feedback que você recebeu produziu alguma mudança?

22- Você recebeu algum acompanhamento pós treinamento da UniAzul? E de seu gestor? 


\section{Apêndice 4}

\section{Entrevista UniAzul}

1- Por qual motivo a UniAzul foi criada? Quais seus objetivos?

2- Como a UniAzul está estruturada? Qual o público alvo? Há envolvimento dos gestores? Eles atuam como multiplicadores?

3- Há algum material escrito que eu possa ter acesso?

4- Qual a relação da UniAzul com a Azul? Qual a relação entre os interesses da Azul e o conteúdo ministrado na UniAzul?

5- Como é feita a avaliação dos treinamentos?

6- Como é medida a eficácia do que foi aprendido em sala de aula? Como é o feedback quando os funcionários voltam para suas bases?

7- Você enxerga que a Azul tem alguma vantagem competitiva em relação a seus concorrentes devido à existência da UniAzul?

8- Você enxerga que a Azul tem um retorno financeiro satisfatório por conta do investimento na UniAzul?

9- Você acredita que a UniAzul perpetua a existência da Azul através da transmissão de sua herança cultural?

10- Como é selecionado e atualizado o conteúdo dado em aula? Como são selecionados os assuntos/matérias abordado (as)? Como é selecionado o conteúdo de EAD? O curso é com base em competências? Quais?

11- "Portanto, define-se Universidade Corporativa como "um sistema de desenvolvimento de pessoas pautado pela gestão de pessoas por competências". (Eboli, 2004). " Pode-se dizer que a UniAzul é uma Universidade Corporativa? 